\title{
Wildlife vulnerability and risk maps for combined pollutants
}

\author{
Joost Lahr ${ }^{1}$, Bernd Münier², Marieke de Lange ${ }^{1}$, Steen Gyldenkaerne ${ }^{2}$, \\ Jack Faber ${ }^{1} \&$ Peter Borgen Sørensen ${ }^{3}$
}

\section{Maps for single compounds}

1.Construct a habitat map for the area of interest $\rightarrow$ habitat map

2.Use ecological vulnerability analysis to determine the average vulnerability score of each habitat based on the wildlife species associated with it (de Lange et al, Environ. Toxicol. Chem., in press, DOI 10.1897/08-626.1)

3.Map the (relative) average vulnerability of the habitats based on this vulnerability analysis $\rightarrow$ vulnerability map

4. Make a (relative) hazard map by dividing the (bioavailable) environmental concentrations of the pollutant by a toxic threshold concentration or an Environmental Quality Standard $\rightarrow$ hazard map

5. Construct a (relative) risk map by multiplying vulnerability and hazard for each pixel on the map $\rightarrow$ risk map

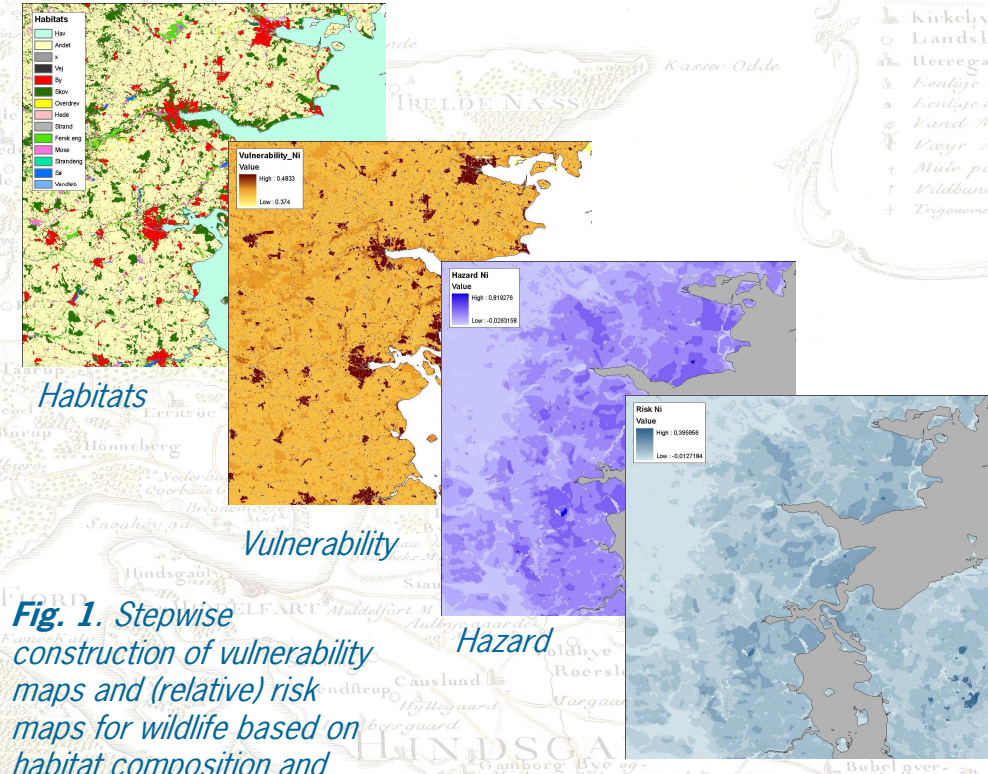

habitat composition and

vulnerability analysis.

Example for nickel in soil.
Risk

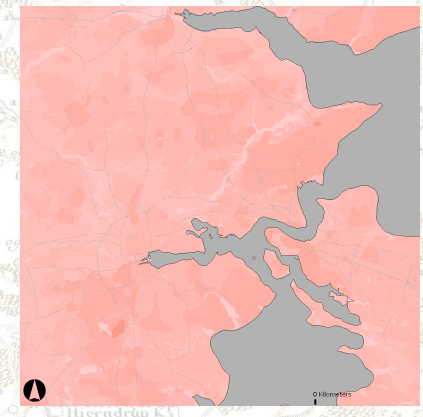

Antagonism

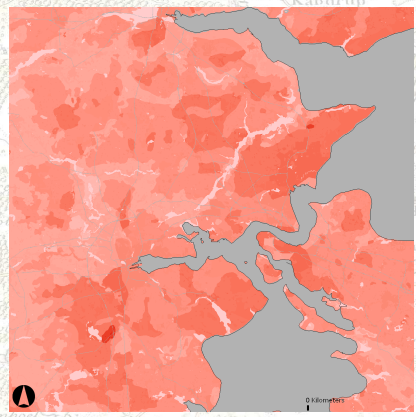

Concentration addition

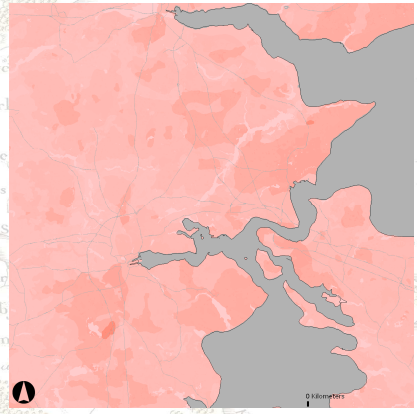

No addition

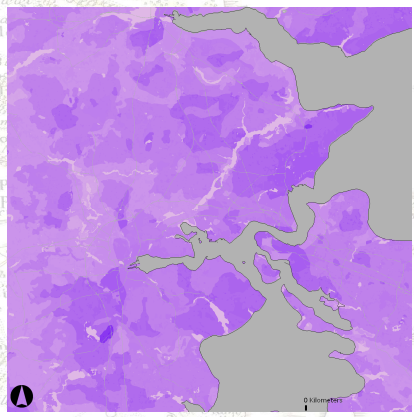

Synergism

\section{Maps for combinations of} compounds

From the (relative) risk maps for individual components, maps for the combined risk can be constructed. The method depends on the type of compounds and their joint action.

Examples for different modes of joint action (Fig. 2):

-No addition - in each pixel of the map, the compound with the highest risk determines the overall risk.

- Concentration addition - in each pixel the (relative) risks of the individual compounds are added.

-Antagonism - for each pixel the relative risks are multiplied with a factor $<1$ and then added.

- Synergism - for each pixel the relative risks are multiplied with a factor $>1$ and then added.

Fig. 2. Relative risk maps assuming different modes of joint action. Example for the metals nickel, cadmium, copper and zinc in soil. 